\title{
Exposure Flow Rate
}

National Cancer Institute

\section{Source}

National Cancer Institute. Exposure Flow Rate. NCI Thesaurus. Code C83071.

The velocity or speed of an exposure. 